\title{
УДК 81.11
}

DOI: $10.18384 / 2310-712 X-2020-2-78-85$

\section{ЯЗЫКОВАЯ ИГРА КАК ПРОБЛЕМА ПЕРЕВОДА}

\section{Руденко Е. С., Бачиева Р. И.}

${ }^{1}$ Донской государственный технический университет 344000 , г. Ростов-на-Дону, пл. Гагарина, д. 1, Российская Федерация

2 Ростовский государственный экономический университет (РИНХ) 344002, г. Ростов-на-Дону, ул. Б. Садовая, д. 69, Российская Федерация

\section{Аннотация.}

Цель работы - исследовать способы передачи языковой игры, нацеленные на достижение максимального комического эффекта.

Процедура и методы исследования. На базе языковых средств, извлечённых из пьесы А. П. Чехова «Медведь», был произведён анализ приёмов воссоздания языковой игры. В качестве методов исследования применялись метод контекстологического анализа и сравнительно-сопоставительный метод.

Результаты проведённого исследования. Особенностью комического у А. П. Чехова является использование окказиональных лексем и окказиональных фразеологизмов; приоритетным при переводе данных единиц является сохранение формы при условии, что не утрачивается эфффект комического воздействия.

Теоретическая и практическая значимость заключается в дальнейшей теоретической разработке методики переводческого анализа и в возможности использования предложенных переводческих решений в практической деятельности переводчика.

Ключевые слова: языковая игра, художественный текст, переводческая стратегия

\section{WORDPLAY AS A TRANSLATION PROBLEM}

\section{E. Rudenko', R. Bachieva ${ }^{2}$}

${ }^{1}$ Don State Technical University

1 ploshad Gagarina, Rostov-on-Don 344000, Russian Federation

${ }^{2}$ Rostov State University of Economic

69 ulitsa Bolshaya Sadovaya, Rostov-on-Don 344002, Russian Federation

\section{Abstract.}

Purpose is to study the ways of achieving maximum comic impact when transferring wordplay into a target language.

Methodology and Approach. The author has conducted a detailed analysis of techniques for recreating wordplay by using language units from Chekhov's play „The Bear“. This has been achieved by means of the method of contextual analysis and the comparative method.

Results. Distinctive qualities of Chekhov's literary style in terms of humorous content are occasional phraseological units and occasional lexemes. In translating, the highest priority is assigned to the form provided that comic impact is preserved.

Theoretical and/or Practical implications lie in the further development of translation analysis technology and in using the proposed translational decisions in practical translational activities.

Keywords: wordplay, work of fiction, translation strategy

(ㄷ СС ВҮ Руденко Е. С., Бачиева Р. И., 2020. 
Произведения А. П. Чехова относятся к тем, что составляют золотой фонд русской литературы. Своеобразный тонкий юмор - неотъемлемый компонент стиля А. П. Чехова, который сумел значительно расширить рамки комического и обогатить средства его художественного выражения. Уникальная комбинаторика языковых средств составляет существенный признак авторского стиля писателя, особенно это касается случаев языковой игры. Проблема адекватного перевода языковой игры является весьма активно разрабатываемой $[4 ; 8]$. Поиск путей совершенствования стратегий перевода продиктован необходимостью адекватного отражения в переводе индивидуально-авторской картины мира, что указывает на актуальность данного исследования.

Языковая игра - понятие, которое ввёл в научный оборот Л. Витгенштейн, понимая под этим термином «единое целое: язык и действия, с которыми он переплетен» [1, с. 83]. В данном исследовании языковая игра рассматривается как объект лингвопереводческого анализа, поэтому за основу взято более узкое понимание этого термина, сформулированное С. Ж. Нуховым: языковая игра это «такая форма речевого поведения человека, при которой языковая личность, реализуя свои лингвокреативные способности, демонстрирует свой индивидуальный стиль» [7, с. 137].

Материалом исследования является текст пьесы А. П. Чехова «Медведь. Шутка в одном действии» и её переводы на английский и немецкий язык. Объектом исследования выступают лексические средства, использующиеся для создания языковой игры, предметом исследования являются способы воссоздания индивидуального авторского стиля и конкретноисторического своеобразия национального колорита произведения в тексте перевода. С целью увеличения репрезентативности выборки в исследовании даётся два варианта английского перевода и два варианта немецкого перевода. При анализе языкового материала использовались метод лингвистического описания, метод сегментного анализа текста и сравнительно-сопоставительный метод.

Сопоставительный анализ приёмов реализации языковой игры в пьесе А. П. Чехова при переводе на английский и немецкий языки позволит выявить оптимальные переводческие решения, ориентированные на достижение максимального комического эффекта, что и является иелью данного исследования. Для достижения поставленной цели решаются следующие задачи:

1) выявление авторских языковых средств, используемых для создания эффекта языковой игры в пьесе А. П. Чехова «Медведь»;

2) установление специфики реализации комического, присущей литературному стилю А. П. Чехова;

3) анализ приёмов передачи комического в переводах пьесы А. П. Чехова «Медведь» на английский и немецкий языки с точки зрения их адекватности исходному тексту.

Основные проблемы теории перевода в значительном числе случаев сводятся к конфликту между формальным соответствием и функциональной эквивалентностью текста перевода тексту оригинала. В переводоведении в настоящее время существует полемический конфликт между двумя теориями перевода, которые подробно рассматривается в работе Л. Э. Найдич и А. В. Павловой, - это теория эквивалентности и скопос-теория [6]. Данные теории остаются предметом дискуссий, постепенно обнаруживая свои сильные и слабые стороны. Кристиана Норд отмечает, что основной проблемой теории эквивалентности была расплывчатость понятия - эквивалентность понималась как «инвариантность на уровне плана содержания» [9], «инвариантность функциональных доминант текста» [12] и т. д. К концу 1970-х гг. наметилась смена переводческой парадигмы: фокус сме- 
стился с исходного текста на переводной текст [10, р. 567]. По мнению А. С. Десницкого, скопос-теория «предложила твердые основания для теоретического анализа всего спектра переводов, заведомо не ставя одни из них в положение правильных (как теория функционального эквивалента), и дала возможность осознанно выбирать между моделями, а также оценивать каждый перевод по подходящим ему критериям» [3, с. 98].

В нашем исследовании мы опираемся на концепцию перевода, сформулированную профессором Л. К. Латышевым. Он исходит из определённого набора требований, которым должен удовлетворять «хороший» перевод, среди которых главенствующее место занимает «максимально достижимая степень семантикоструктурного подобия исходному тексту (при наличии эквивалентности регулятивного воздействия исходного текста и переводного текста)» [5, с. 31-33]. В данном исследовании под наличием эквивалентности регулятивного воздействия исходного текста и переводного подразумевается способность переводного текста вызывать у адресата смеховую реакцию, равноценную смеховой реакции от исходного текста.

Л.К. Латышев, формулируя требования к полноценному переводу, ссылается на работу В. Г. Гака и Ю. И. Львин, в которой постулируется, что «переводной текст должен максимально полно воспроизводить не только смысл и содержание оригинала, но и его структуру и стиль с особенностями речи автора (и его героев)» $[2$, c. 9]. Для нас принципиально важна эта позиция, оберегающая текст оригинала от искажений и именуемая в скопос-теориии лояльностью (верностью) по отношению к исходному тексту [11, p. 123]. В противном случае придётся говорить не о переводе, а о других видах языкового посредничества - различных формах адаптации и переработки информации.

Пьеса «Медведь» была написана А. П. Чеховым в феврале 1888 г. «Мед- ведь» - пьеса из жизни русского провинциального дворянства, призванная вскрыть алогизм жизни. Действие происходит в одной из помещичьих усадеб. Помещик Смирнов пытается в весьма грубой форме взыскать с неутешной вдовы Поповой долг её покойного мужа. Между ними завязывается словесная перебранка, в ходе которой Смирнов вызывает Попову на дуэль. Отчаянная решимость Поповой приводит Смирнова в восторг, он влюбляется, «как гимназист», оказываясь в роли укрощённого медведя.

Обратимся к табл. 1 и проанализируем первый фрагмент исходного текста, содержащий элемент языковой игры.

Каламбурное выражение «должен буду вылететь в трубу вверх ногами» представляет собой семантический синтез двух компонентов: фразеологического оборота "вылететь в трубу» и устойчивого сочетания "вверх ногами», которое подчёркивает неправильное положения тела в пространстве и усиливает экспрессивную окраску рассматриваемого выражения, понимаемого как «полностью разориться». Сохранение обеих частей исходного выражения не представляется возможным в силу различия фразеологических систем русского, английского и немецкого языков. Вариант перевода "to make a graceful exit from this life feet first" представляется наименее удачным из всех, поскольку в нём утрачена динамическая импульсивность и нервная взвинченность речи главного героя (Смирнова), вызывающе грубое поведение которого отсылает к названию произведения. Варианты "to fly up the chimney with my feet in the air" и "mit den Füßen nach oben durch den Schornstein werde fliegen müssen" сохраняют образную основу выражения и тем самым достигают до некоторой степени комического эффекта, но утрачивают компонент смысла «разориться». В варианте "mit Pauken und Trompeten bankrott gehe”, как и в предыдущих случаях, утрачен элемент языковой игры, совершенно утерян комический эффект оригинала 


\section{Таблииа 1 / Table 1}

\section{Сравнительная таблица оригинальных фрагментов пьесы \\ А. П. Чехова «Медведь» и их переводов на английский и немецкий языки}

\section{Comparative table of original fragments from A. Chekhov's The Bear and the translations into English and German}

\begin{tabular}{|c|c|c|c|c|c|}
\hline \begin{tabular}{|l|l} 
№ \\
\end{tabular} & $\begin{array}{c}\text { Оригинал } \\
(\text { А. П. Чехов })^{1}\end{array}$ & $\begin{array}{c}\text { Перевод } \\
\text { (Julius West) }^{2}\end{array}$ & $\begin{array}{c}\text { Перевод } \\
\text { (Hilmar } \\
\text { Baukage) }^{3} \\
\end{array}$ & $\begin{array}{c}\text { Перевод } \\
\text { (Hannelore } \\
\text { Umbreit) }^{4}\end{array}$ & 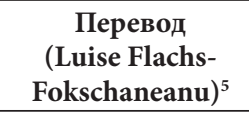 \\
\hline 1 & \begin{tabular}{|l} 
А у меня теперь \\
такое настроение, \\
что если я завтра \\
не заплачу про- \\
центов, то должен \\
буду вылететь \\
в трубу вверх \\
ногами. У меня \\
опишут имение!
\end{tabular} & $\begin{array}{l}\text { And I'm in a state } \\
\text { of mind which, if I } \\
\text { don't pay the inter- } \\
\text { est due to-morrow, } \\
\text { will force me to } \\
\text { make a graceful } \\
\text { exit from this life } \\
\text { feet first. They'll } \\
\text { take my estate! }\end{array}$ & \begin{tabular}{|l|} 
And I am in the \\
mood to fly up \\
the chimney with \\
my feet in the air \\
if I can't lay hands \\
on that interest \\
to-morrow. They'll \\
sequestrate my \\
estate!
\end{tabular} & \begin{tabular}{|l|} 
Und ich bin \\
augenblicklich \\
in einer solchen \\
Stimmung, \\
daß ich, wenn ich \\
morgen nicht mei- \\
ne Zinsen zahle, \\
mit \\
Pauken und \\
Trompeten bank- \\
rott gehe. Dann \\
kommt \\
mein Gut unter \\
den Hammer!
\end{tabular} & $\begin{array}{l}\text { Und ich befinde } \\
\text { mich in einer Stim- } \\
\text { mung, daß ich, } \\
\text { wenn ich } \\
\text { morgen die Zinsen } \\
\text { nicht einzahle, mit } \\
\text { den Füßen nach } \\
\text { oben durch den } \\
\text { Schornstein werde } \\
\text { fliegen müssen. } \\
\text { Man wird mein Gut } \\
\text { sequestrieren! }\end{array}$ \\
\hline 2 & \begin{tabular}{|l|} 
От злости все \\
поджилки тря- \\
сутся и дух захва- \\
тило.
\end{tabular} & $\begin{array}{l}\text { All my inside is } \\
\text { quivering with } \\
\text { anger, and I can't } \\
\text { even breathe. }\end{array}$ & $\begin{array}{l}\text { Every tendon is } \\
\text { trembling with } \\
\text { anger and I can } \\
\text { hardly breathe. }\end{array}$ & \begin{tabular}{|l|} 
So wütend, daß \\
mir sämtliche Glie- \\
der zittern und ich \\
keine Luft mehr \\
kriege. \\
\end{tabular} & $\begin{array}{l}\text { Vor Bosheit zittern } \\
\text { mir alle Sehnen- } \\
\text { bänder und der } \\
\text { Atem versagt mir. }\end{array}$ \\
\hline 3 & $\begin{array}{l}\text { Настоящая жен- } \\
\text { ская, турнюрная } \\
\text { логика! }\end{array}$ & $\begin{array}{l}\text { That's real silly } \\
\text { feminine logic. }\end{array}$ & $\begin{array}{l}\text { Pure woman's } \\
\text { logic. }\end{array}$ & \begin{tabular}{|l|} 
Das nenn' ich \\
echte Weiberrock- \\
Logik!
\end{tabular} & $\begin{array}{l}\text { Echte Frauenlogik, } \\
\text { Turnürelogik! }\end{array}$ \\
\hline 4 & $\begin{array}{l}\text { Разлимонился, } \\
\text { рассиропился, } \\
\text { раскис. }\end{array}$ & $\begin{array}{l}\text { I'm weak, I'm } \\
\text { wax, I've melted. }\end{array}$ & $\begin{array}{l}\text { I am conquered, } \\
\text { lost. }\end{array}$ & \begin{tabular}{|l|} 
Kein Gedanke \\
mehr an Wut, der \\
reinste Sirup, But- \\
ter in der Sonne. \\
\end{tabular} & $\begin{array}{l}\text { Ich bin besiegt, } \\
\text { verloren. }\end{array}$ \\
\hline 5 & $\begin{array}{l}\text { Пять лет не влю- } \\
\text { блялся, дал себе } \\
\text { зарок, и вдруг } \\
\text { втюрился, как } \\
\text { оглобля в чужой } \\
\text { кузов! }\end{array}$ & $\begin{array}{l}\text { I haven't been in } \\
\text { love for five years, } \\
\text { I'd taken a vow, } \\
\text { and now all of } \\
\text { a sudden I'm in } \\
\text { love, like a fish } \\
\text { out of water! }\end{array}$ & $\begin{array}{l}\text { For five years I } \\
\text { haven't been in } \\
\text { love, I thanked } \\
\text { the Lord for it and } \\
\text { now I am caught, } \\
\text { like a carriage } \\
\text { tongue in another } \\
\text { carriage. }\end{array}$ & $\begin{array}{l}\text { Fünf Jahre war ich } \\
\text { nicht verliebt, } \\
\text { hatte es mir ge- } \\
\text { schworen ... Und } \\
\text { dann das hier, } \\
\text { Hals } \\
\text { über Kopf! }\end{array}$ & $\begin{array}{l}\text { Fünf Jahre lang } \\
\text { habe ich mich nicht } \\
\text { verliebt, ich habe es } \\
\text { mir gelobt und nun } \\
\text { bin ich mit einem } \\
\text { Mal hineingeraten, } \\
\text { wie die Deichsel } \\
\text { in einen fremden } \\
\text { Kutschkasten! }\end{array}$ \\
\hline
\end{tabular}

\footnotetext{
Чехов А. П. Медведь // Интернет-библиотека Алексея Комарова. URL: https://ilibrary.ru/text/996/p.1/index. html (дата обращения: 19.01.2020).

2 Chekhov A. The Bear [Электронный ресурс] / transl. J. West. URL: https://www.gutenberg.org/files/7986/7986h/7986-h.htm\#link2H_4_0005 (дата обращения: 19.01.2020).

3 Tchekoff A. The Boor [Электронный pecypc] / transl. H. Baukage. URL: http://www.gutenberg.org/files/36984/ 36984-h/36984-h.htm\#THE_BOOR (дата обращения: 19.01.2020).

4 Tschechow A. Der Bär [Электронный ресурc] / aus dem Russischen von Hannelore Umbreit. URL: https://www. dtver.de/downloads/leseprobe/e----429.pdf (дата обращения: 19.01.2020).

5 Tschechow A. Der Bär / transl. L. Flachs-Fokschaneanu // Internet Archive. URL: https://archive.org/stream/derbrgroteskeine22494gut/pg22494.txt (дата обращения: 19.01.2020).
} 
при сохранении содержательной стороны и сниженной стилистической окраски.

Во втором фрагменте текста А. П. Чехова идиома «поджилки трясутся» вступает в семантический конфликт с лексемой «злость» и как следствие создаёт комичный эффект. Во всех приведённых вариантах переводчики применили приём семантического калькирования, но в данном случае установление соответствия между идиоматическими словосочетаниями двух языков привело бы к меньшим потерям в плане воссоздания юмористического эффекта: "I'm shaking in my shoes with anger", "So wütend, daß ich weiche Knien habe".

Третий фрагмент текста отсылает читателя к предмету женского гардероба турнюру, «модной в 80-х годах XIX в. принадлежности женского платья в виде подушечки, подкладывавшейся под ткань сзади ниже талии для придания фигуре пышности» ${ }^{2}$. Данный элемент гардероба фигурирует в качестве окказионального компонента фразеологизма «женская логика» в системе рассматриваемого художественного произведения. Словосочетание фразеологического характера «женская логика» имеет следующее значение: «о суждениях, отличающихся отсутствием логичности, основанных не на доводах рассудка, а на чувствах» ${ }^{2}$. Посредством метонимического переноса с части на целое («предмет женского гардероба» - «женщина») узуальный фразеологизм приобретает качественное своеобразие и преобразуется в окказиональный фразеологизм «турнюрная логика». В вариантах перевода, выполненных Юлием Уэстом и Хилмаром Баукхаге, адъективная лексема «турнюрная» полностью утрачена, а вместе с ней, во-первых, утрачена отсылка к значимой культурно-исторической реалии того времени, во-вторых, нивелирована осо-

Турнюр // Пчелкина В. В. Словарь иностранных слов. М.: Русский язык, 1984. С. 512.

2 Женская логика // Горбачевич К. С. Словарь современного русского литературного языка. T. V-VI, Е-3. М.: Русский язык, 1991. С. 105. бенность авторского стиля: “That's real silly feminine logic", "Pure woman's logic". B немецких вариантах перевода "Das nenn" ich echte Weiberrock-Logik!", "Echte Frauenlogik, Turnürelogik!” сохранен семантический компонент «предмет одежды», в первом случае наблюдается расширение значения исходной лексемы (Weiberrock «юбка»), во втором случае даётся семантически точный перевод Turnürelogik. Немецким вариантам перевода присуща большая степень адекватности оригиналу, что обусловлено словообразовательными возможностями немецкого языка, в котором словосложение является ведущей моделью образования новых слов. В английском языке логико-смысловые связи между словами также могут быть реализованы посредством модели $\mathrm{N}+\mathrm{N}$, но они в большей степени характерны для сложных слов-терминов. Однако такая словообразовательная модель не противоречит системе языка, поэтому в целях сохранения авторского образного арсенала мы считаем возможным перевести словосочетание "турнюрная логика» как "bustle logic", "petticoat logic".

В четвёртом фрагменте текста глаголы составляют градационный ряд, реализующий повышение интенсивности эмоционального состояния. Приставка раз- (рас-) в русском языке вносит значение постепенного нарастания действия и доведения его до чрезмерной степени. В английских вариантах перевода утрачен стилистический эффект нагнетания признака, реализующийся посредством повтора приставки раз- (рас-), что приводит к снижению прагматического потенциала комического воздействия. Принимая во внимание сценичность речи персонажа, представляется возможным сохранение динамичности высказывания посредством использования глагола get, который (среди прочих) имеет значение "to become or start to be"з и до некоторой

\footnotetext{
3 Cм.: Get // Cambridge Dictionary: [сайт]. URL: https://dictionary.cambridge.org/ru/словарь/англо-русский/get (дата обращения: 19.01.2020).
} 
степени компенсирует утраченное значение приставки раз- (раc-): I'm getting syrupy, mushy, mawkish. Немецкий вариант перевода "Ich bin besiegt, verloren" семантически и структурно повторяет английский вариант перевода "I am conquered, lost". Второй вариант немецкого перевода содержательно более точен, но в нём ослаблены динамичность и компактность подачи материала, присущая оригиналу: "Kein Gedanke mehr an Wut, der reinste Sirup, Butter in der Sonne”.

Окказиональное образное выражение в пятом фрагменте текста «втюрился, как оглобля в чужой кузов» восходит к пословицам, в которых содержится яркий эмоционально-оценочный компонент, «догружающий» прямое значение слова «влюбиться»: «Влюбился, как сажа в рожу, влепился / Влюбился, как мышь в короб ввалился / Втюрился, как рожей в лужу» ${ }^{1}$. Как видно из примеров, значение глагола «влюбиться» частично коррелирует со значением глагола «попасть» (провалиться, упасть куда-либо). Поэтому максимально адекватным ори-

1 Любовь - нелюбовь // Даль В. И. Пословицы русского народа: в 2 ч. Ч. 2. М.: Юрайт, 2019. С. 204. гиналу мы считаем английский и немецкий варианты перевода, сохранившие образный смысл чеховского выражения: "now I am caught, like a carriage tongue in another carriage", "nun bin ich mit einem Mal hineingeraten, wie die Deichsel in einen fremden Kutschkasten!". В остальных вариантах переводчики воспользовались приёмом образной замены окказионального оборота узуальным (be like a fish out of water; Hals über Kopf), пожертвовав при этом авторским стилем и комическим эффектом.

В табл. 2 схематично отражена степень адекватности перевода исходным фрагментам текста («+» - максимальная адекватность перевода оригиналу, «+ -»- частичная адекватность (утрата комического эффекта при сохранении авторского словоупотребления, сохранение комического эффекта при частичной нивелировке авторской образности), «-» - неадекватный перевод.

Как показывает проведённый выше анализ, языковые средства, используемые автором для создания эффекта языковой игры, требуют тщательной проработки переводческой стратегии. Особенностью реализации комического,

Таблица 2

\section{Сравнительная таблица адекватности перевода оригинальным фрагментам пьесы А. П. Чехова «Медведь»}

Table 2

\section{Comparison of translation adequacy}

\begin{tabular}{|c|l|c|c|c|c|}
\hline № & \multicolumn{1}{|c|}{$\begin{array}{c}\text { Оригинал } \\
\text { (А.П. Чехов) }\end{array}$} & $\begin{array}{c}\text { Перевод } \\
\text { (Julius West) }\end{array}$ & $\begin{array}{c}\text { Перевод } \\
\text { (Hilmar } \\
\text { Baukage) }\end{array}$ & $\begin{array}{c}\text { Перевод } \\
\text { (Hannelore } \\
\text { Umbreit) }\end{array}$ & $\begin{array}{c}\text { Перевод } \\
\text { (Luise Flachs- } \\
\text { Fokschaneanu) }\end{array}$ \\
\hline 1 & $\begin{array}{l}\ldots \text { то должен буду вылететь в тру- } \\
\text { бу вверх ногами! }\end{array}$ & +- & +- & +- & +- \\
\hline 2 & $\begin{array}{l}\text { От злости все поджилки трясутся } \\
\text { и дух захватило. }\end{array}$ & +- & +- & +- & +- \\
\hline 3 & $\begin{array}{l}\text { Настоящая женская, турнюрная } \\
\text { логика! }\end{array}$ & - & - & + & + \\
\hline 4 & $\begin{array}{l}\text { Разлимонился, рассиропился, } \\
\text { раскис. }\end{array}$ & +- & +- & +- & +- \\
\hline 5 & $\begin{array}{l}\ldots \text { и вдруг втюрился, как оглобля } \\
\text { в чужой кузов! }\end{array}$ & - & + & - & + \\
\hline
\end{tabular}


присущей литературному стилю А. П. Чехова, является использование окказиональных фразеологических образований (втюрился, как оглобля в чужой кузов) и окказиональных лексем с пейоративной семантикой (турнюрная тогика). Окказиональные фразеологизмы ставят переводчика перед необходимостью выбора между формой и содержанием, которые оказываются неразрывно связанными. В примере № 1 переводчики сделали выбор в пользу формы, сохранив тем самым авторскую образность и комический эффект, потери содержания компенсируются последующим контекстом (They'll take my estate!; Dann kommt mein Gut unter den Hammer). Данная стратегия является выигрышной, поскольку попытки узуальной замены окказионального оборота ведут к большим содержательно-смысловым и прагматическим потерям, как показывает проанализированный пример № 5. Применительно к узуальным фразеологизмам (пример № 2) самым верным переводческим решением является замена узуального фразеологизма в исходном тексте равноценным фразеологизмом в переводящем языке. Игнорирование авторских окказионализмов (пример № 3) сводит к нулю художественные достоинства текста и является неприемлемым с точки зрения лояльности переводчика по отношению к автору и читателю. Таким образом, перефразируя Дэна Брауна, можно сказать, что переводимо (почти) всё, на непереводимое просто требуется больше времени.

Статья поступила в редакиию 24.01.2020

\section{ЛИТЕРАТУРА}

1. Витгенштейн Л. Философские исследования // Витгенштейн Л. Философские работы. Ч. І. М.: Гнозис, 1994. С. 75-319.

2. Гак В. Г., Львин Ю. И.Курс перевода: Французский язык. М.: Международные отношения, 1970. $400 \mathrm{c}$.

3. Десницкий А. С. Современный библейский перевод: теория и методология. М.: Издательство Православного Свято-Тихоновского гуманитарного университета, 2015. 432 с.

4. Ласкова М. В., Попова Ю. В. Лингвокультурные особенности языковой игры в рекламной картине мира: монография. Ростов н/Д.: ИПО ЮФУ, 2013. 128 с.

5. Латышев Л. К. Технология перевода. М.: Академия, 2005. 320 с.

6. Найдич Л. Э., Павлова А. В. Трубочист или лорд? Теория и практика немецко-русского и русско-немецкого перевода. СПб.: Златоуст, 2015. 408 с.

7. Нухов С. Ж. Языковая игра в словообразовании. На материале лексики английского языка: дис. ... докт. филол. наук. М., 1997. 372 с.

8. Руденко Е. С. Этнокультурный компонент юмора: сохранить нельзя заменить // Вестник Московского государственного областного университета. Серия: Лингвистика. 2019. № 3. С. 93-102.

9. Kade O. Qualitätsstufen der Übersetzung // Fremdsprachen. 1964. No. 4. S. 250-260.

10. Nord C. Function + Loyalty: Theology Meets Skopos // Open Theology. 2016. Vol. 2. Iss. 1. P. 566-580.

11. Nord C. Translating as a Purposeful Activity. Functionalist Approaches Explained. Manchester: St. Jerome, 1997. $154 \mathrm{p}$.

12. Reiss K. Texttyp und Übersetzungsmethode: Der operative Text. Kronberg: Scriptor, 1976. 146 S.

\section{REFERENCES}

1. Wittgenshtein L. [Philosophical studies]. In: Wittgenshtein L. Filosofskie raboty. Ch. I [Philosophical works. Part I]. Moscow, Gnozis Publ., 1994, pp. 75-319.

2. Gak V. G., L'vin Yu. I. Kurs perevoda: Frantsuzskii yazyk [The course of translation: French]. Moscow, Mezhdunarodnye otnosheniya Publ., 1970. 400 p.

3. Desnitsky A. S. Sovremennyi bibleiskii perevod: teoriya i metodologiya [Modern biblical translation: theory and methodology]. Moscow, St. Tikhon's Orthodox University Publ., 2015. 432 p.

4. Laskova M. V., Popova Yu. V. Lingvokul'turnye osobennosti yazykovoi igry v reklamnoi kartine mira [Linguocultural peculiarities of the wordplay in the advertising picture of the world]. Rostov on Don, Southern Federal University Publ., 2013. 128 p. 
5. Latyshev L. K. Tekhnologiya perevoda [Translation technology]. Moscow, Akademiya Publ., 2005. $320 \mathrm{p}$.

6. Naidich L. E., Pavlova A. V. Trubochist ili lord? Teoriya i praktika nemetsko-russkogo i russko-nemetskogo perevoda [Chimney sweep or a Lord? Theory and practice of German-Russian and Russian-German translation]. St. Petersburg, Zlatoust Publ., 2015. 408 p.

7. Nukhov S. Zh. Yazykovaya igra v slovoobrazovanii. Na materiale leksiki angliiskogo yazyka: dis.... dokt. filol. nauk [Language play in word formation. On the basis of English language vocabulary: D. thesis in Philological Sciences]. Moscow, 1997. 372 p.

8. Rudenko E. S. [Ethnocultural component of humor: retain or replace]. In: Vestnik Moskovskogo gosudarstvennogo oblastnogo universiteta. Seriya: Lingvistika [Bulletin of Moscow Region State University. Series: Linguistics], 2019, no. 3, pp. 93-102.

9. Kade O. Qualitätsstufen der Übersetzung. In: Fremdsprachen, 1964, no. 4, S. 250-260.

10. Nord C. Function + Loyalty: Theology Meets Skopos. In: Open Theology, 2016, vol. 2, iss. 1, pp. 566580.

11. Nord C. Translating as a Purposeful Activity. Functionalist Approaches Explained. Manchester, St. Jerome, 1997. $154 \mathrm{p}$.

12. Reiss K. Texttyp und Übersetzungsmethode: Der operative Text. Kronberg, Scriptor, 1976. 146 S.

\section{ИНФОРМАЦИЯ ОБ АВТОРАХ}

Руденко Елена Сергеевна - кандидат филологических наук, доцент кафедры научно-технического перевода и профессиональной коммуникации Донского государственного технического университета; e-mail: RudenkoElena1988@yandex.ru

Бачиева Рупия Изитдиновна - кандидат филологических наук, доцент кафедры иностранных языков для экономических специальностей Ростовского государственного экономического университета (РИНХ);

e-mail: gamzatartur4004@gmail.com

\section{INFORMATION ABOUT THE AUTHORS}

Elena S. Rudenko - PhD in Philological Sciences, Assistant Professor at the Department of scientific and technical translation and professional communication, Don State Technical University; e-mail: RudenkoElena1988@yandex.ru

Rupija I. Bachieva - PhD in Philological Sciences, Assistant Professor at the Department of Foreign languages for economic specialties, Rostov State University of Economics (RINH);

e-mail: gamzatartur4004@gmail.com

\section{ПРАВИЛЬНАЯ ССЫЛКА НА СТАТЬЮ}

Руденко Е. С., Бачиева Р. И. Языковая игра как проблема перевода // Вестник Московского государственного областного университета. Серия: Лингвистика. 2020. № 2. С. 78-85.

DOI: $10.18384 / 2310-712 \mathrm{X}-2020-2-78-85$

\section{FOR CITATION}

Rudenko E. S., Bachieva R. I. Wordplay as a translation problem. In: Bulletin of Moscow Region State University. Series: Linguistics, 2020, no. 2, pp. 78-85.

DOI: $10.18384 / 2310-712 \mathrm{X}-2020-2-78-85$ 